\title{
Multiferroic broken by commensurate magnetic ordering in terbium orthomanganite
}

\author{
Hao Zhang, ${ }^{[\mathrm{a}]}$ Roxana Flacau,${ }^{[\mathrm{b}]}$ Xin Du, ${ }^{[\mathrm{a}]}$ Pascal Manuel, ${ }^{[\mathrm{c}]}$ Junzhuang Cong, ${ }^{[\mathrm{d}]}$ Young Sun, ${ }^{[\mathrm{d}]}$ Junliang \\ Sun, ${ }^{[\mathrm{a}]}$ Sihai Yang, ${ }^{[\mathrm{e}]}$ Guobao Li, ${ }^{\left[{ }^{[a]}\right.}$ Fuhui Liao, ${ }^{\left[{ }^{[a]}\right.}$ and Jianhua Lin ${ }^{*[a]}$ \\ Dedication (multiferroic)
}

\begin{abstract}
TbMnO}_{3}$ is an important multiferroic showing strong coupling between magnetic and ferroelectric orderings. Incommensurate magnetic ordering is suggested to be vital for this coupling in $\mathrm{TbMnO}_{3}$, which can be modified by doping at the site of $\mathrm{Tb}$ and/or Mn. Our study shows that a self-doped solid solution $\mathrm{Tb}_{1}$. ${ }_{x} \mathrm{Mn}_{\mathrm{y}} \mathrm{MnO}_{3}(\mathrm{y} \leq \mathrm{x})$ can be formed with $\mathrm{Mn}$ doped into the site of $\mathrm{Tb}$ of $\mathrm{TbMnO}_{3}$. When $\mathrm{y}$ is very small $\mathrm{Tb}_{1-x} \mathrm{Mn}_{\mathrm{y}} \mathrm{MnO}_{3}$ shows both ferroelectric and incommensurate magnetic orders at low temperature, which is similar to $\mathrm{TbMnO}_{3}$. However, if $\mathrm{y}$ is large enough, a commensurate antiferromagnetic ordering appears along with the incommensurate magnetic ordering to prevent the appearance of multiferroicity in $\mathrm{Tb}_{1-x} \mathrm{Mn}_{\mathrm{y}} \mathrm{MnO}_{3}$. That is to say, the magnetoeletric coupling can be broken by the co-existence of a commensurate antiferromagnetic ordering. This finding may be useful to the study of $\mathrm{TbMnO}_{3}$.
\end{abstract}

Multiferroic is a material showing two or more orderings such as ferroelectric, ferromagnetic, and/or ferroelastic ordering at the same time ${ }^{[1]}$ with potential applications in information storage, spintronics, and sensors. ${ }^{[2]}$ Strong magnetoelectric coupling is very desirable to help the easy control of polarization by changing magnetic field or vice versa, and has been found in some multiferroics such as $\mathrm{TbMnO}_{3}$, ${ }^{[3 \mathrm{a}]} \mathrm{TbMn}_{2} \mathrm{O}_{5},{ }^{[3 \mathrm{~b}]}$ and $\mathrm{Ni}_{3} \mathrm{~V}_{2} \mathrm{O}_{8}{ }^{[3 \mathrm{c}]}$ Incommensurate antiferromagnetic (ICAM) ordering is reported to be the key element for this strong coupling in $\mathrm{TbMnO}_{3}:{ }^{[4]}$ the electric polarization in $\mathrm{TbMnO}_{3}$ is induced by this ICAM ordering. Herein, we report that the coexistence of a commensurate antiferromagnetic (CAM) ordering can destroy this coupling in $\mathrm{Tb}_{1-x} \mathrm{Mn}_{\mathrm{y}} \mathrm{MnO}_{3}$. To our knowledge, this is the first report on such phenomenon, which may add new knowledge to understand the nature of the strong coupling in $\mathrm{TbMnO}_{3}$.

[a] H. Zhang, X.Du, J. L. Sun, G.B. Li, F. H. Liao, J. H. Lin Beijing National Laboratory for Molecular Sciences, State Key Laboratory of Rare Earth Materials Chemistry and Applications, College of Chemistry and Molecular Engineering, Peking University, Beijing 100871, P. R. China.

E-mail: liguobao@pku.edu.cn,.Jhlin@pku.edu.cn

[b] R. Flacau

Canadian Neutron Beam Centre

Chalk River Laboratories, ON, K0J 1J0, Canada

[c] P. Manuel

ISIS Neutron Facility, STFC Rutherford Appleton Laboratory,

Chilton, Oxfordshire, OX11 0QX (UK)

[d] J. Zh. Cong, Y. Sun

Institute of Physics Chinese Academy of Sciences

Beijing, 100190, P.R. China

[e] S.H.Yang

School of Chemistry University of Nottingham University Park, Nottingham NG7 2RD, UK

Supporting information for this article is given via a link at the end of the document.
Eight samples (listed in Table 1) were synthesized by the solid state reaction. ${ }^{[5]}$ Neutron powder diffraction analysis shows that they all crystallize in orthorhombic Pnma at room temperature, which is in good agreement with the X-ray diffraction findings (Fig.1a, 1b and 1e with more details listed in Supporting Information(SI)). To monitor possible temperature induced structural and/or magnetic phase transitions, neutron and X-ray powder diffraction patterns were collected at various temperatures between $3.5 \mathrm{~K}$ and $290 \mathrm{~K}$, and $12 \mathrm{~K}$ and $298 \mathrm{~K}$ respectively. While no changes have been observed in the $\mathrm{X}$-ray diffraction patterns measured down to $12 \mathrm{~K}$ (Fig.1e,1f) except small shift caused by the changes of the lattice parameters, several new reflections ( $A, B$, and/or $C$ in Fig.1c and 1d) appeared in the neutron powder diffraction patterns of all samples collected at temperatures below $50 \mathrm{~K}$. Hence, these reflections are attributed to magnetic orderings. ${ }^{[3 a, 5 b, 6]}$ The magnetic reflections related to $A, B$ and $C$ are attributed to the ICAM ordering of Tb with a wave vector $\boldsymbol{q}_{\mathrm{Tb}}=(\sim 0.415,0,0)$ and of $\mathrm{Mn}$ with a wave vector $\boldsymbol{q}_{\mathrm{Mn}}=(\sim 0.283,0,0)$ in the space group Pna2 1 setting, ${ }^{[3 a, 6]}$ and the CAM ordering of both $\mathrm{Tb}$ and $\mathrm{Mn}$ in the magnetic space group $P n^{\prime} a 2_{1}{ }^{\prime},{ }^{[5 b]}$ and noted as ICAM

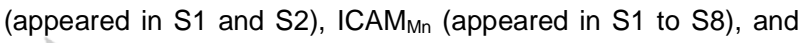
$\mathrm{CAM}_{\mathrm{Tb}+\mathrm{Mn}}$ (appeared in S4 to $\mathrm{S} 8$ ) respectively.
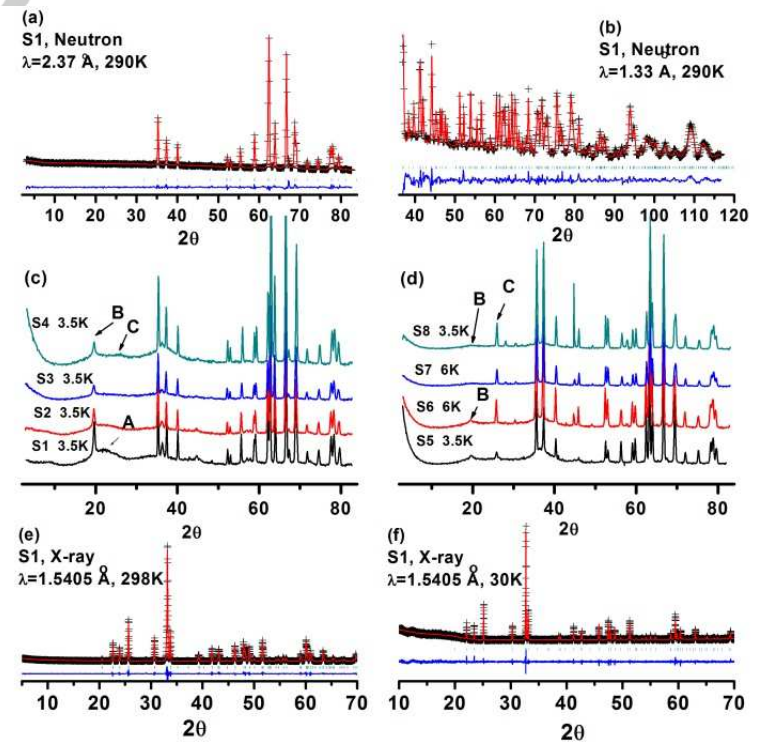

Figure 1. Typical diffraction patterns for $S 1$ to $S 8$ : Rietveld plot of neutron powder diffraction (NPD) data (a, b), and of X-ray powder diffraction (XRD) data $(e, f)$ for S1; NPD data for S1 to S8 $(c, d)$. The refinement details are listed in SI. NPD data were collected on the C2 High Resolution Powder Diffractometer at Canadian Neutron Beam Centre (Chalk River, Canada).XRD data were obtained on a Rigaku Smartlab configured in high resolution mode (Ge200 double bounce monochromator). 
Table 1. The composition of the samples with formula $\left(\mathrm{Tb}_{1-\mathrm{x}} \mathrm{Mn}_{\mathrm{y}}\right) \mathrm{MnO}_{3}$

\begin{tabular}{lllllllll}
\hline & $S 1^{\mathrm{a}}$ & $\mathrm{S} 2$ & $\mathrm{~S} 3$ & $\mathrm{~S} 4$ & $\mathrm{~S} 5$ & $\mathrm{~S} 6$ & $\mathrm{S7}$ & $\mathrm{S} 8$ \\
\hline $\mathrm{x}^{\mathrm{b}}$ & 0.040 & 0.056 & 0.073 & 0.089 & 0.106 & 0.122 & 0.139 & 0.155 \\
$\mathrm{y}^{\mathrm{b}}$ & 0.005 & 0.024 & 0.044 & 0.063 & 0.082 & 0.102 & 0.121 & 0.140 \\
\hline
\end{tabular}

[a]the sample name; [b] $x, y$ is corresponding to the formula $\left(\mathrm{Tb}_{1-\mathrm{x}} \mathrm{Mn}_{\mathrm{y}}\right) \mathrm{MnO}_{3}$. To save the space, the error of (1) is not attached. The data are obtained by chemical titration and Rietveld refinements of the neutron diffraction data. The details of the above method have been published previously. ${ }^{[5]}$

Transition temperatures for magnetic ordering ICAMTb, $\mathrm{ICAM}_{\mathrm{Mn}}$ and $\mathrm{CAM}_{\mathrm{Tb}+\mathrm{Mn}}$ (noted as $\mathrm{T}_{\text {ICAM }}{ }^{\mathrm{Tb}}, \mathrm{T}_{\mathrm{ICAM}^{\mathrm{Mn}}}{ }^{\mathrm{Mn}}$, and $\mathrm{T}_{\mathrm{CAM}}{ }^{\mathrm{Tb}+\mathrm{Mn}}$ ) can be determined from the neutron diffraction patterns. As

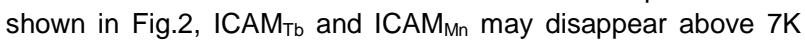
and $42 \mathrm{~K}$ for $\mathrm{S} 1$; ICAM $_{\mathrm{Mn}}$ and $\mathrm{CAM}_{\mathrm{Tb}+\mathrm{Mn}}$ disappear above $30 \mathrm{~K}$ and $47 \mathrm{~K}$ for S8. Then, $\mathrm{T}_{\text {ICAM }}{ }^{\mathrm{Tb}}$ is about $7 \mathrm{~K}$ for $\mathrm{S} 1$; $\mathrm{T}_{\text {ICAM }}{ }^{\mathrm{Mn}}$ is about 42 and $30 \mathrm{~K}$ for $\mathrm{S} 1$ and $\mathrm{S} 8 ; \mathrm{T}_{\mathrm{CAM}}{ }^{\mathrm{Tb}+\mathrm{Mn}}$ is about $47 \mathrm{~K}$ for $\mathrm{S} 8$. Similarly, $\mathrm{T}_{\text {ICAM }}{ }^{\mathrm{Tb}}$ is about $5 \mathrm{~K}$ for S2; $\mathrm{T}_{\text {ICAM }}{ }^{\mathrm{Mn}}$ is about $40,39,37$, 35,35 , and $33 \mathrm{~K}$ for $\mathrm{S} 2, \mathrm{~S} 3, \mathrm{~S} 4, \mathrm{~S} 5, \mathrm{~S} 6$, and S7 respectively; $\mathrm{T}_{\text {CAM }}{ }^{\mathrm{Tb}+\mathrm{Mn}}$ is about 40,42 , and 46 for S5, S6, and S7 respectively (see $\mathrm{SI}$ ). Although the reflections corresponding to $\mathrm{CAM}_{\mathrm{Tb}+\mathrm{Mn}}$ can be observed for S4 (Fig.1), they are too weak to make sure at which temperature they disappear. Therefore, $T_{C A M}{ }^{T b+M n}$ is not reported for S4. All the obtained neutron diffraction data can be refined well as shown in Fig. $2 \mathrm{c}$ and $2 \mathrm{~d}$ (the details are listed in $\mathrm{SI})$ : the data without magnetic reflections are refined with only the nuclear structure (noted as model $\mathrm{N}$ ); the data, showing only $I_{C A M}$ or $\mathrm{CAM}_{\mathrm{Tb}+\mathrm{Mn}}$, are refined with both $\operatorname{ICAM}_{\mathrm{Mn}}($ model $\mathrm{B}$ ) or $\mathrm{CAM}_{\mathrm{Tb}+\mathrm{Mn}}$ (model $\mathrm{C}$ ), and model $\mathrm{N}$; the data, showing both $I C A M_{M n}$ and ICAM the three phase models (model $A$ (for magnetic ordering $A$ ), model $\mathrm{B}$ and model $\mathrm{N}$; or model $\mathrm{C}, \mathrm{B}$ and $\mathrm{N}$ ).
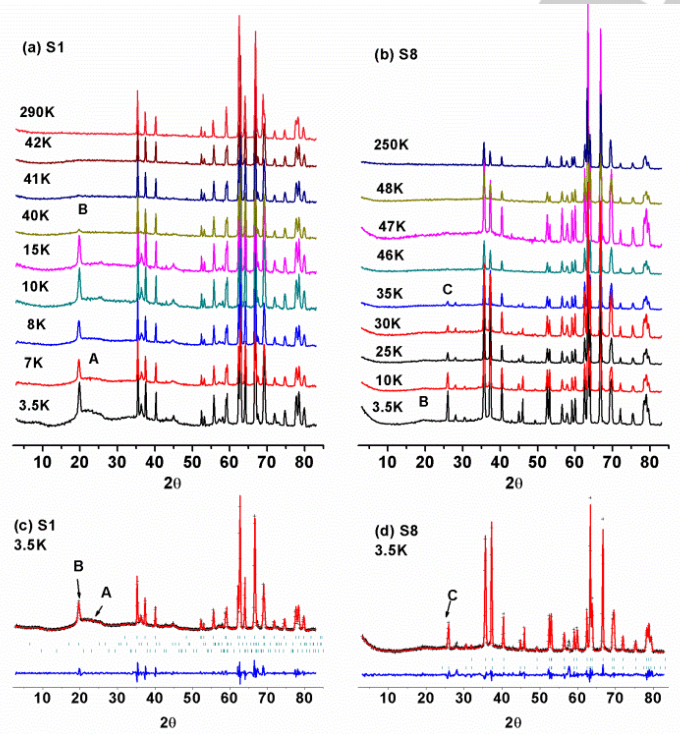

Figure 2. Neutron diffraction data collected for $S 1$ (a) and $S 8$ (b) at selected temperatures, and the Rietveld plot of neutron diffraction data of S1 (c) and S8 (d) at $3.5 \mathrm{~K}$. The refinement details were listed in SI. $\lambda=2.37 \AA$.
From the above Rietveld refinements, the lattice parameters, ordered magnetic moments of $\mathrm{ICAM}_{\mathrm{Mn}}$ and $\mathrm{CAM}_{\mathrm{Tb}+\mathrm{Mn}}$, and the wave vector $q_{M n}$ for $I C A M_{M n}$ of the studied samples can be obtained. It is found that the change of the lattice parameter $c$ is very interesting while the lattice parameter $b$ monotonically decreases with the increase of temperature and the lattice parameter $a$ increases with several slopes. For example, as shown in Fig.3a, the lattice parameter $c$ of $S 1$ decreases from 3.5 to $10 \mathrm{~K}$ when the temperature increases; after that it increases to about $25 \mathrm{~K}$ in a flat slope, to about $43 \mathrm{~K}$ in a different slope, and to about $70 \mathrm{~K}$ in the third slope. Three characteristic temperatures, $\sim 10 \mathrm{~K}, \sim 25 \mathrm{~K}$ and $\sim 43 \mathrm{~K}$, were found. The temperature about $10 \mathrm{~K}$ and $43 \mathrm{~K}$ can be related to $\mathrm{T}_{\text {ICAM }}{ }^{\text {Tb }}$ and $\mathrm{T}_{\text {ICAM }}{ }^{\mathrm{Mn}}$, respectively. The temperature $\sim 25 \mathrm{~K}$ can be related to the change of $\boldsymbol{q}_{\mathrm{Mn}}$ for ICAM $\mathrm{Mn}_{\mathrm{Mn}}$ (Fig.3a4, and notes as $\mathrm{T}_{\boldsymbol{q}}{ }^{\mathrm{Mn}}$ ): $\boldsymbol{q}_{\mathrm{Mn}}$ may be constant when the temperature is lower than $\sim 25 \mathrm{~K}\left(\mathrm{~T}_{q}^{\mathrm{Mn}}\right)$ and increases slightly when the temperature is higher than $\sim 25 \mathrm{~K}$ $\left(\mathrm{T}_{q}{ }^{\mathrm{Mn}}\right)$. It may be also related to the paraelectric to ferroelectric phase transition temperature of $\mathrm{S} 1$ as shown in Fig.3e1, which is similar to $\mathrm{TbMnO}_{3}$, and had been noted as $\mathrm{T}_{\text {lock. }}{ }^{[3 \mathrm{a}]}$ The note $\mathrm{T}_{\text {lock }}$ is also adopted by us now. Although no reliable value of $\boldsymbol{q}_{\mathrm{Mn}}$ can be obtained for the samples S5 to S8 due to the weak corresponding magnetic reflections, and the paraelectric to ferroelectric phase transition has not been found for the samples S4 to S8. The $T_{\text {Lock }}$ for S8 is also around 25K (Fig.3b3). Similar changes of the lattice parameter $c$ can also be found for S2 to S7 (see SI for the details), which agrees well with the data reported by J. Blasco et al. ${ }^{[7]}$ for $\mathrm{TbMnO}_{3}$ or by I.V. Golosovsky et al. ${ }^{[8]}$ for $\mathrm{Tb}_{0.95} \mathrm{Bi}_{0.05} \mathrm{MnO}_{3}$. The $\mathrm{T}_{\text {Lock }}$ for each sample is presented in Fig.4.
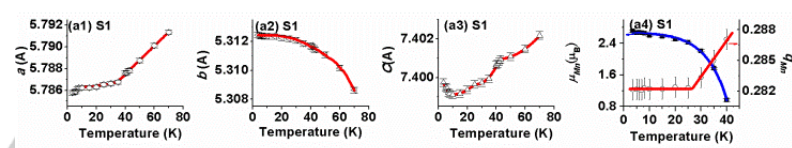

5.704

$\frac{5.704}{5.700}$
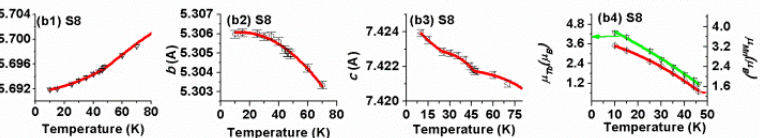

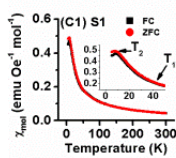
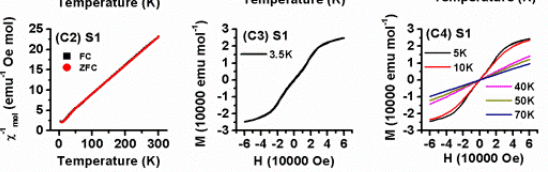

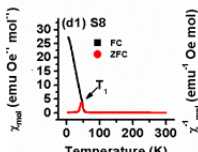
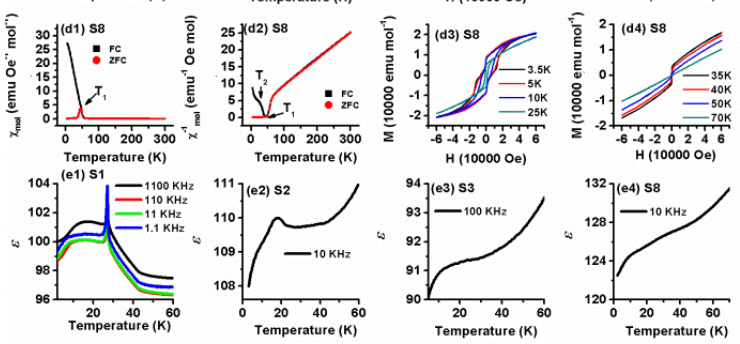

Figure 3. Temperature dependent lattice parameters of $\mathrm{S} 1(\mathrm{a} 1, \mathrm{a} 2, \mathrm{a} 3)$ and $\mathrm{S} 8$ (b1,b2,b3); ordered magnetic moment of $\mathrm{Mn}$ and $\mathrm{q}_{\mathrm{Mn}}$ of $\mathrm{S} 1$ (a4); ordered magnetic moment of $\mathrm{Tb}$ and $\mathrm{Mn}$ of magnetic ordering $\mathrm{C}$ in S8 (b4); magnetic susceptibility $\left(\chi_{\mathrm{mol}}\right)$, inverse magnetic susceptibility $\left(\chi_{\mathrm{mol}}{ }^{-1}\right)$, and $\mathrm{M}-\mathrm{H}$ curve of $\mathrm{S} 1$ $(\mathrm{C} 1, \mathrm{C} 2, \mathrm{C} 3$, and C4) and S8 (d1, d2, d3, and 4); dielectric susceptibility of S1 (e1), S2(e2), S3(e3), and S8(e4). 
The temperature dependence of the magnetic susceptibilities varies from $\mathrm{S} 1$ to $\mathrm{S} 8$. Two characteristic temperatures $T_{1}$ and $T_{2}$ are found and marked in Fig.3c and $3 \mathrm{~d}$. The zero field cooling (ZFC) and field cooling (FC) curves of the temperature dependent magnetic susceptibility are overlapped from the temperature $T_{1}$ to room temperature for all the samples. The Curie-Weiss law is agreed well from the temperature a little above $T_{1}$ to room temperature (shown in $\mathrm{SI}$ ). Below $T_{1}$ the $\mathrm{FC}$ curve departures from the ZFC curve, which is the feature of the ferromagnetism (including weak ferromagnetism such as canted anti-ferromagnetism). ${ }^{[9]}$ The departure becomes larger and larger from $\mathrm{S} 1$ to $\mathrm{S} 8$. $T_{1}$ agrees well with the temperature where the magnetic reflections just appear in the neutron diffraction data (See Fig. 2 and $\mathrm{SI}$ ). For $\mathrm{S} 1$ to $\mathrm{S} 3, T_{1}$ corresponds to $\mathrm{T}_{\text {ICAM }}{ }^{\mathrm{Mn}}$. However, it is a little difficult to find $T_{1}$ for $\mathrm{S} 1$ to $\mathrm{S} 3$ only according to the temperature dependent magnetic susceptibility. The departure of the FC curve from the ZFC curve at $T_{1}$ is very small. At this case, one may argue that the additional reflections appeared in the data collected around $40 \mathrm{~K}$ comparing to the data collected around $298 \mathrm{~K}$ is due to a non-magnetic phase transition and the very small departure of the FC curve from the ZFC curve is due to the error of measurement. However, these additional reflections were not observed in the X-ray diffraction data of $\mathrm{S} 1$ (Fig.1f) collected at $30 \mathrm{~K}$, which confirmed that these additional reflections were magnetic related and the corresponding phase transition is a magnetic phase transition. In fact, this is the typical case for $\mathrm{TbMnO}_{3}$, which has been reported by many researchers. ${ }^{10-12}$ For $S 4, T_{1}$ corresponds the temperature where the FC and ZFC curves start to depart, which is a little higher than $\mathrm{T}_{I_{C A M}}{ }^{\mathrm{Mn}}$, and may be the ordering temperature of $\mathrm{CAM}_{\mathrm{Tb}+\mathrm{Mn}}\left(\mathrm{T}_{\mathrm{CAM}}{ }^{\mathrm{Tb}+\mathrm{Mn}}\right)$. For $\mathrm{S} 5$ to $\mathrm{S} 8, T_{1}$ corresponds to $\mathrm{T}_{\mathrm{CAM}}{ }^{\mathrm{T}+\mathrm{Mn}}$. It is almost the peak temperature in the curve of temperature dependent magnetic susceptibility of the corresponding sample for S6 to S8. However, it is a little higher than the peak temperature in the curve of temperature dependent magnetic susceptibility for S5. After careful checking, one may find a very small departure of FC curve from the ZFC curve at $T_{1}$ for S5.

$T_{2}$ is related to the first peak (from left to right in Fig.3a1) for the curve of the temperature dependent magnetic susceptibility for $S 1$ to $S 5$, and the first peak for the curve of the temperature dependent invert magnetic susceptibility for S6 to S8. It is found that $T_{2}$ is around the ordering temperature of ICAM $\mathrm{ID}_{\mathrm{Tb}}$ for both $\mathrm{S} 1$ and $\mathrm{S} 2$, and the ordering temperature of $\mathrm{ICAM}_{\mathrm{Mn}}$ for $\mathrm{S} 5$ to $\mathrm{S} 8$.

The field dependent magnetization $(\mathrm{M}-\mathrm{H})$ curves for $\mathrm{S} 1$ at $3.5 \mathrm{~K}$ and for $\mathrm{S} 2$ at $5 \mathrm{~K}$ seem just curved lines with a very narrow gap, which agrees well with the small departure of the ZFC curve from the $\mathrm{FC}$ curve. The $\mathrm{M}-\mathrm{H}$ loops show a clear butterfly shape around $5 \mathrm{~K}$ for $\mathrm{S} 3$ to $\mathrm{S} 8$, indicating that the samples are metamagnetic at low temperature, which is similar to that reported for $\mathrm{TbMnO}_{3}{ }^{[13]}$ When the temperature increases to about $T_{2}$, the $\mathrm{M}-\mathrm{H}$ loops become normal indicating that at these temperatures the reported materials are normal canted antiferromagnetic. When the temperature is above $T_{1}$, the loop disappears and the $\mathrm{M}-\mathrm{H}$ curve is just a line. The saturated ferromagnetic moments of nearly $5 \mu_{\mathrm{B}}$ per formula unit are found for $\mathrm{S} 1$ to $\mathrm{S} 8$, which is comparable to that for $\mathrm{TbMnO}_{3}{ }^{[13]}$
At present, it is a little difficult to obtain the electrical hysteresis for ceramic materials at low temperature because our low temperature system uses a small amount of helium as heat transfer medium to make the sample to be cooled to the low temperature, which prevent the use of high voltage (above $\sim 1000 \mathrm{~V}$ ) needed to measure the electrical hysteresis of ceramic samples. However, it is lucky that when the electrical hysteresis is found for a certain compound below the temperature $T_{P}$ a $\lambda$ type peak of $\varepsilon$ (dielectric constant) should be found around $T_{p}$. Therefore, the temperature dependent $\varepsilon$ is measured to check the ferroelectricity of the samples. The pronounced $\lambda$-type peak of $\varepsilon$ is found at around 27 and $21 \mathrm{~K}$ for $\mathrm{S} 1$ and S2 respectively as shown in Fig3e, which is similar to that reported for $\mathrm{TbMnO}_{3}$. ${ }^{\text {[3a] }}$ This may indicate that $\mathrm{S} 1$ and $\mathrm{S} 2$ become ferroelectric below those temperatures. No $\lambda$-type peak of $\varepsilon$ is found between 5 and $60 \mathrm{~K}$ for S3, S4, S5, S6, S7, and S8 (see SI). The direct measurement of the ferroelectricity by hysteresis is still needed.

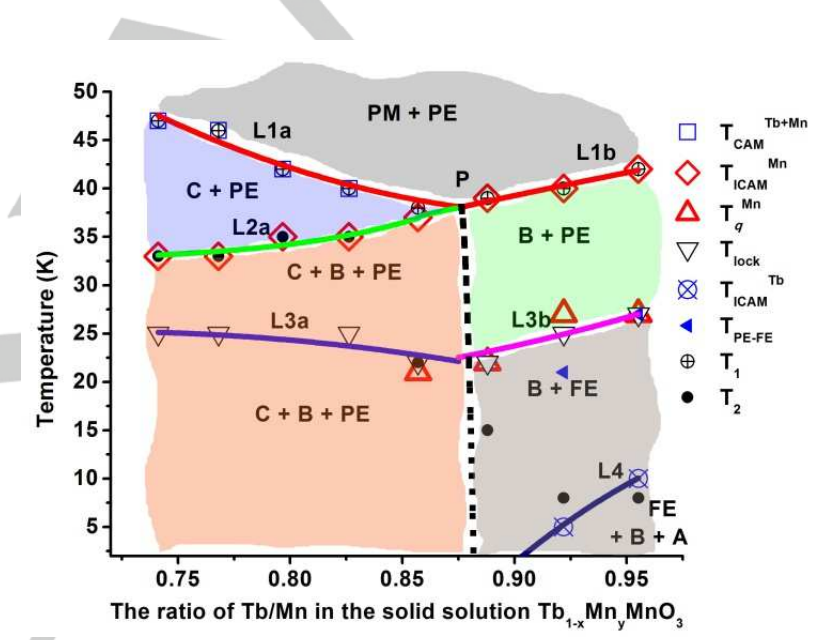

Figure 4. Phase diagram of $\left(\mathrm{Tb}_{1-x} \mathrm{Mn}_{\mathrm{y}}\right) \mathrm{MnO}_{3-\delta}$. $\mathrm{PM}$, paramagnetic; $\mathrm{PE}$, paraelectric; FE, ferroelectric; A, B, C, magnetic ordering of ICAM ${ }_{T b}, I_{C A M}$, and $\mathrm{CAM}_{\mathrm{Tb}+\mathrm{Mn}}$, respectively; $\mathrm{T}_{\text {ICAM }}{ }^{\mathrm{Tb}}, \mathrm{T}_{\mathrm{ICAM}}{ }^{\mathrm{Mn}}, \mathrm{T}_{\mathrm{CAM}}{ }^{\mathrm{Tb}+\mathrm{Mn}}$, ordering temperature of ICAM $\mathrm{Tb}_{\mathrm{Tb}}, \mathrm{ICAM}_{\mathrm{Mn}}$, and $\mathrm{CAM}_{\mathrm{Tb}+\mathrm{Mn}}$, respectively; $\mathrm{T} 1, \mathrm{~T} 2, \mathrm{~T}_{\text {lock}}$, see details in text; $\mathrm{T}_{\mathrm{PE}+\mathrm{FE}}$, paraelectric to ferroelectric phase transition temperature; $\mathrm{T}_{q}{ }^{\mathrm{Mn}}$, the anomaly temperature of $q_{M n}$.

In conclusion, an overview of the information obtained above can be summarized in Fig.4. It is clear that all the samples have the same nuclear crystal structures as $\mathrm{TbMnO}_{3}$ and are paramagnetic and paraelectric (marked as $\mathrm{PM}+\mathrm{PE}$ ) in the area above the line of $T_{1}$ for the samples. This line consists of two parts: one is the ordering temperature of $\operatorname{ICAM}_{\mathrm{Mn}}(\mathrm{L} 1 \mathrm{~b})$, the other is the ordering temperature of $\mathrm{CAM}_{\mathrm{Tb}+\mathrm{Mn}}(\mathrm{L} 1 \mathrm{a})$. The two parts join at the point $P$. The present data could not give the exact position of $\mathrm{P}$, but it should be between S3 $\left(\mathrm{Tb}_{0.927} \mathrm{Mn}_{0.044} \mathrm{MnO}_{3}\right)$ and $\mathrm{S} 4\left(\mathrm{~Tb}_{0.911} \mathrm{Mn}_{0.063} \mathrm{MnO}_{3}\right)$. A dash curve from $\mathrm{P}$ can be drawn in the figure 4 to separate two areas: the sample on the left (S4 to $\left.\mathrm{S} 8\left(\mathrm{~Tb}_{0.845} \mathrm{Mn}_{0.140} \mathrm{MnO}_{3}\right)\right)$ shows $C A M_{T b+M n}$ ordering, and the sample on the right does not show $\mathrm{CAM}_{\mathrm{Tb}+\mathrm{Mn}}$ ordering. Below $\mathrm{L} 1 \mathrm{a}$, the ordering temperature of ICAM $\mathrm{Mn}_{\mathrm{n}}$ for S4 to S8 forms a line $\mathrm{L} 2 \mathrm{a}$. The samples show $\mathrm{CAM}_{\mathrm{Tb}+\mathrm{Mn}}$ ordering only with 
paraelectric property between $\mathrm{L} 1 \mathrm{a}$ and $\mathrm{L} 2 \mathrm{a}$ (noted as $\mathrm{C}+\mathrm{PE}$ ). The line L2a joins with L1b smoothly, which may indicate that the change of $\mathrm{ICAM}_{\mathrm{Mn}}$ in the whole solid solution is monotonic.

The $T_{\text {lock }}$ of the studied samples forms the line 3 in Fig.4, which is also divided by the dash line into two parts, L3a and L3b. It is found that the paraelectric to ferroelectric phase transition temperature of $\mathrm{S} 1 \quad\left(\mathrm{~Tb}_{0.960} \mathrm{Mn}_{0.005} \mathrm{MnO}_{3}\right)$ and $\mathrm{S} 2$ $\left(\mathrm{Tb}_{0.956} \mathrm{Mn}_{0.024} \mathrm{MnO}_{3}\right)$ is also around the line L3b, which may mean that this line separates the paraeletric phase from the ferroelectric phase. Really a round peak around $20 \mathrm{~K}$ has been found in the curve of $\varepsilon$ as shown in Fig.3e3, which may mean that a weak ferroelctricity exists in $\mathrm{S} 3\left(\mathrm{~Tb}_{0.927} \mathrm{Mn}_{0.044} \mathrm{MnO}_{3}\right)$. However, no paraelectric to ferroelectric phase transition occurs around L3a for S4 $\left(\mathrm{Tb}_{0.911} \mathrm{Mn}_{0.063} \mathrm{MnO}_{3}\right)$ to S8 $\left(\mathrm{Tb}_{0.845} \mathrm{Mn}_{0.140} \mathrm{MnO}_{3}\right)$. Then on the right of the dash line the area between $L 1 b$ and $L 3 b$ is marked as B+PE indicating that the samples in this area are paraelectric with magnetic ordering $I_{C A M}$ and the area below L3b is marked as B+FE showing that the corresponding samples are ferroelectric with magnetic ordering ICAM $\mathrm{Mn}_{\mathrm{M}}$. On the left of the dash line the area below the line $\mathrm{L} 2 \mathrm{a}$ is marked as $\mathrm{B}+\mathrm{C}+\mathrm{PE}$ to indicate the samples are paraelectric with both magnetic ordering $\mathrm{ICAM}_{\mathrm{Mn}}$ and $\mathrm{CAM}_{\mathrm{Tb}+\mathrm{Mn}}$ The line L3a may not separate the paraelectric from the ferroelectric from present results. The physical nature of this line is not clear at present. The ordering temperatures of ICAM form the line L4, which decreases with the increase of Mn doped in $\mathrm{Tb}$ site. Then it is reasonable to expect that the ordering temperature of $\mathrm{ICAM}_{\mathrm{Tb}}$ for $\mathrm{S} 3\left(\mathrm{~Tb}_{0.927} \mathrm{Mn}_{0.044} \mathrm{MnO}_{3}\right)$ to S8 $\left(\mathrm{Tb}_{0.845} \mathrm{Mn}_{0.140} \mathrm{MnO}_{3}\right)$ is too low to be observed. The area below this line is marked as $\mathrm{A}+\mathrm{B}+\mathrm{FE}$ to show that the samples are ferroelectric with both magnetic ordering $I_{C A M}$ and ICAM $M_{M n}$.

The above observation can be abstracted a conclusion that the appearance of the commensurate magnetic ordering $\mathrm{CAM}_{\mathrm{Tb}+\mathrm{Mn}}$ should cause a loss of a magnetically switchable polarization (magnetoelectric effects) and therefore the multiferroicity is broken. At this case, one may understand the behaviour of the sample S4: although only very weak magnetic reflections corresponding to magnetic ordering $\mathrm{CAM}_{\mathrm{Tb}+\mathrm{Mn}}$ were observed with strong magnetic reflections related to magnetic ordering $\mathrm{ICAM}_{\mathrm{Mn}}$, no ferroelectricity was observed. At the same time, ferroelectricity has been observed in samples $\mathrm{S} 1\left(\mathrm{~Tb}_{0.960} \mathrm{Mn}_{0.005} \mathrm{MnO}_{3}\right)$ and S2 $\left(\mathrm{Tb}_{0.956} \mathrm{Mn}_{0.024} \mathrm{MnO}_{3}\right)$ where strong magnetic reflections related to magnetic ordering ICAM are observed without reflections related to magnetic ordering

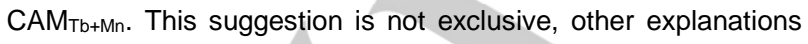
may be possible.

\section{Acknowledgements}

This work is supported by National Key Basic Research Project of China (2010CB833103) and the National Natural Science Foundation of China ( Grants 11275012, 21271014).

Keywords: multiferroic $\cdot$ neutron diffraction $\cdot$ commensuarte antiferromagnetic ordering $\cdot$ phase diagram $\bullet$ self doping
[1] a) H.Schmid, Ferroelectrics 1994, 162, 317-338; b) W.Eerenstein, N. D. Mathur, J. F. Scott, 2006, 442, 759-765; c) N. A. Spaldin, S. W. Cheong, R. Ramesh, Phys. Today 2010, 63, 38-43.

[2] a) N. Hur, S. Park, P. A. Sharma, J. S. Ahn, S. Guha, S. W. Cheong, Nature 2004, 429,392-395; b) K. Z. Rushchanskii, S. Kamba, V. Goian, P. Vanek, M. Savinov, J. Prokleska, D. Nuzhnyy, K. Knizek, F. Laufek, S. Eckel, S. K. Lamoreaux, A. O. Sushkov, M. Lezaic, N. A. K. Spaldin, Nat. Mater. 2010, 9, 649-654; c) Y. Tokura, J. Magn. Magn. Mater. 2007, 310, 1145-1150.

[3] a) T. Kimura, T. Goto, H. Shintani, K. Ishizaka, T. Arima, Y. Tokura, Nature 2003, 426, 55-58. b) N. Hur, S. Park, P. A. Sharma, J. S. Ahn, S. Guha, S. W. Cheong, Nature 2004, 429, 392-395. c) G. Lawes, A. B. Harris, T. Kimura, N. Rogado, R. J. Cava, A. Aharony, O. EntinWohlman, T. Yildirim, M. Kenzelmann, C. Broholm, A. P. Ramirez, Phys. Rev. Lett. 2005, 95, 087205.

[4] a) M. Mostovoy, Phys. Rev. Lett. 2006, 96, 067601. b) H. Katsura, N. Nagaosa, A. V. Balatsky, Phys. Rev. Lett. 2005, 95, 057205.

[5] a) R. Wang, C. X. Yang, M. Fan, M. M. Wu, C. H. Wang, X. H. Yu, J. L. Zhu, J. R. Zhang, G. B. Li, Q. Z. Huang, D. F. Chen, T. N. Jin, T. Kamiyama, F. H. Liao, J. H. Lin, J. Alloy. Compd. 2013, 554, 385-394; b) H. Zhang, R. Flacau, J. L. Sun, G. B. Li, F. H. Liao, J. H. Lin, Inorg. Chem. 2014, 53, 4535-4540.

[6] S. Quezel, F. Tcheou, J. Rossatmignod, G. Quezel, E. Roudaut, Physica $B$ \& C 1977, 86, 916-918.

[7] J. Blasco, C. Ritter, J. Garcia, J. M. de Teresa, J. Perez-Cacho, M. R. Ibarra, Phys. Rev. B 2000, 62, 5609.

[8] I. V. Golosovsky, A. A. Mukhin, V. Y. Ivanov, S. B. Vakhrushev, E. I. Golovenchits, V. A. Sanina, J. U. Hoffmann, R. Feyerherm, E. Dudzik, Eur. Phys. J. B 2012, 85, 103.

[9] a) X. Marti, V. Skumryev, C. Ferrater, M. V. Garcia-Cuenca, M. Varela, F. Sanchez, J. Fontcuberta, Appl. Phys. Lett. 2010, 96, 222505. b) J. S. White, M. Bator, Y. Hu, H. Luetkens, J. Stahn, S. Capelli, S. Das, M. Dobeli, T. Lippert, V. K. Malik, J. Martynczuk, A. Wokaun, M. Kenzelmann, C. Niedermayer, C. W. Schneider, Phys. Rev. Lett. 2013, $111,037201$.

[10] a) T. S. Chan, R. S. Liu, Y. H. Lien, C. C. Yang, C. Y. Huang, J. G. Lin, IEEE Trans. Magn. 2005, 41, 2751-2753. b) T. S. Chan, R. S. Liu, C. C. Yang, W. H. Li, Y. H. Lien, C. Y. Huang, J. W. Lynn, J. M. Chen, H. S. Sheu, Inorg. Chem. 2007, 46, 4575-4582. c) Y. M. Cui, L. W. Zhang, G. L. Xie, R. M. Wang, Solid State Commun. 2006, 138, 481-484. d) C. C. Yang, M. K. Chung, W. H. Li, T. S. Chan, R. S. Liu, Y. H. Lien, C. Y. Huang, Y. Y. Chan, Y. D. Yao, J. W. Lynn, Phys. Rev. B 2006, 74, 094409.

[11] a) F. Perez,; J. Heiras,; R. Escudero, Physica Status Solidi C-Current Topics in Solid State Physics 2007, 4, 4049-4053. b) N. Mufti, A. A. Nugroho, G. R. Blake, T. T. M. Palstra, Phys. Rev. B 2008, 78, 024109. c) M. Pekala, V. Drozd, J. F. Fagnard, P. Vanderbemden, M. Ausloos, J. Alloys Comp. 2009, 467, 35-40. d) N. P. Kumar, G. Lalitha, P. V. Reddy, Physica Scripta 2011, 83, 045701. e) W. Bazela, M. Dul, V. Dyakonov, L. Gondek, A. Hoser, J. U. Hoffmann, B. Penc, A. Szytula, Z. Kravchenko, I. Nosalev, A. Zarzycki, Acta Physica Polonica A 2012, $121,785-788$.

[12] a) V. Dyakonov, A. Szytula, R. Szymczak, E. Zubov, A. Szewczyk, Z. Kravchenko, W. Bazela, K. Dyakonov, A. Zarzycki, V. Varyukhin, H. Szymczak, Low Temp. Phys. 2012, 38, 216-220. b) G. S. Dias, L. G. D. Silveira, L. F. Cotica, I. A. Santos, A. A. Coelho, D. Garcia, J. A. Eirasc, J. A. Sampaio, Scripta Materialia 2014, 89, 65-68. c) R. D. Kumar, M. Subramanian, M. Tanemura, R. Jayavel, J. Nanopart. Res. 2014, 16, 250. d) J. T. Han, Y. H. Huang, W. Huang, J. B. Goodenough, J. Am. Chem. Soc. 2006, 128, 14454-14455. e) X. X. An, J. X. Deng, J. Chen, X. R. Xing, Materials Research Bulletin 2013, 48, 4984-4988.

[13] T. Kimura, G. Lawes, T. Goto, Y. Tokura, A. P. Ramirez, Phys. Rev. B 2005, 71, 224425. 
Entry for the Table of Contents (Please choose one layout)

Layout 1:

COMMUNICATION

With the increase of $\mathrm{Mn}$ in the solid solution $\mathrm{Tb}_{1-x} \mathrm{Mn}_{\mathrm{y}} \mathrm{MnO}_{3}$, a

commensurate antiferromagnetic ordering appears in the sample, which prevents or weakens the

magnetoelectric coupling in this system.

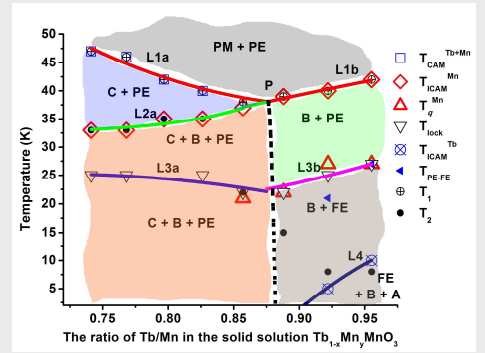

Author(s), Corresponding Author(s)*

Page No. - Page No.

Title 